\begin{tabular}{|c|c|c|}
\hline $\begin{array}{l}\text { PKS } \\
\text { PUBLIC } \\
\text { KNOWLEDGE } \\
\text { PROSECT }\end{array}$ & $\begin{array}{c}\text { REVISTA DE GEOGRAFIA } \\
\text { (RECIFE) } \\
\text { http://www.revista.ufpe.brr/revistageografia }\end{array}$ & $\begin{array}{l}\text { OJS } \\
\text { OPEN } \\
\text { JOUNALA } \\
\text { SYSTEMS }\end{array}$ \\
\hline
\end{tabular}

\title{
A CARTOGRAFIA TEMÁtica COMO SUBSídio PARA O PLANEJAMENTO AMBIENTAL: CIDADE GAÚCHA, PARANÁ
}

\author{
Felipe Rodrigues Macedo ${ }^{1}$, Marta Luzia de Souza ${ }^{2}$
}

${ }^{1}$ Doutorando do Programa de Pós-Graduação em Geografia da Universidade Estadual de Maringá. Email: felipermacedo@outlook.com

${ }^{2}$ Professora Adjunta da Universidade Estadual de Maringá. E-mail: mlsouza@uem.br

Artigo recebido em 20/12/2016 e aceito em 30/01/2018

\section{RESUMO}

Este estudo teve por objetivo utilizar, principalmente, a Cartografia Temática para verificar a relação dos atributos do meio físico com o planejamento ambiental nas áreas urbana e periurbana do município de Cidade Gaúcha, Paraná. Os procedimentos metodológicos que foram adaptados para a área de estudo incluíram três etapas: A revisão bibliográfica e o levantamento dos atributos do meio físico (clima, substrato rochoso, relevo, solos, rede de drenagem e vegetação); a segunda etapa realizada no gabinete consistiu na elaboração dos produtos cartográficos e análise do material obtido; a terceira envolveu os trabalhos de campo. Os resultados mostraram que os produtos cartográficos (gráficos, perfis e cartas temáticas) dos atributos climáticos, aliados com as cartas clinográfica, a morfopedológica, a de uso da terra do ano de 2014, junto ao modelo digital de terreno e os perfis geoecológicos apresentaram a dinâmica do meio físico e a importância desses atributos para o planejamento ambiental. No entanto, percebeu-se que nem sempre esses dados cartográficos básicos que auxiliam na elaboração das cartas temáticas são existentes nos municípios brasileiros ou estão disponíveis em escalas compatíveis para subsidiar o planejamento ambiental e a gestão do território para uma interação equilibrada.

Palavras-Chave: Processos Erosivos, Gestão Ambiental, Noroeste do Paraná.

\section{THE THEMATIC CARTOGRAPHY AS SUPPORT FOR ENVIRONMENTAL PLANNING: CIDADE GAÚCHA, PARANÁ}

\begin{abstract}
This study aimed to use, mainly, the Thematic Cartography to verify the relation between the attributes of the physical environment with the environmental planning in the urban and periurban areas of the municipality of Cidade Gaúcha, Paraná. The methodological procedures that were adapted to the study area included three steps: the bibliographic review and the gathering of the physical environment attributes (climate, rock substrate, relief, soils, drainage network and vegetation); the second stage was done in the office consisted in the elaboration of the cartographic products and analysis of the obtained material; the third involved fieldwork. The results showed that the cartographic products (graphs, profiles and thematic charts) of the climatic attributes, allied with the clinographic, morphopedogical, and land use maps of the year 2014, with the digital ground model and the geoecological profiles presented the dynamics of the physical environment and the importance of these attributes for environmental planning. However, it has been noticed that not always these basic cartographic data that help in the elaboration of the thematic charts are existing in the Brazilian municipalities or they are available in
\end{abstract}


compatible scales to subsidize the environmental planning and the management of the territory for a balanced interaction.

Key Word: Erosive Processes, Environmental Management, Northwest of Paraná.

\section{INTRODUÇÃO}

O planejamento ambiental tem por fundamento a interação e integração dos sistemas que compõem o ambiente. Tem o papel de estabelecer as relações entre os sistemas ecológicos e os processos da sociedade, como também, das necessidades socioculturais a atividades e interesses econômicos, a fim de manter a máxima integridade possível dos seus elementos componentes (SANTOS, 2004).

Para entender a contribuição da cartografia para o planejamento ambiental é necessário fazer uma relação entre a geografia e a cartografia onde já existe uma proximidade entre a ciência do espaço e a área do saber que representa este espaço. É desta relação que se pode entender a contribuição da cartografia ambiental para o planejamento do território (SANTOS, 2009).

Nestas perspectivas a cartografia temática auxilia a elaboração de um planejamento ambiental. No entanto, segundo Botelho (2007), para o conhecimento das reais potencialidades e limitações de uso e ocupação de uma determinada área é preciso obter dados acerca dos seus atributos físicos como: clima, geologia (substrato rochoso), relevo, solos, rede de drenagem e vegetação.

Nunes (2002) realizou o levantamento de informações para caracterizar a paisagem da região de Presidente Prudente - SP e identificar o melhor local para a implantação de um aterro sanitário no município. Este caso demonstra a importância da identificação dos atributos do meio físico para o planejamento ambiental.

O clima é um característica atmosférica a longo prazo de uma determinada área e suas características são geralmente representadas por dados numéricos sobre elementos meteorológicos, tais como temperatura, pressão, vento, precipitação e umidade (THOMAS e GOUDIE, 2000). É o clima que controla o tipo da vegetação e os processos geomorfológicos que operam na paisagem e que podem resultar em erosões e deposições (LEPSCH, 2011).

As características mineralógicas, texturais e estruturais dos corpos rochosos respondem diferentemente a ação dos processos exógenos, influindo nas formas de relevo e tipos de solo. O estudo das propriedades mineralógicas e texturais das rochas permite compreender o avanço da frente de intemperismo, o caminho preferencial percorrido pela água e a existência de descontinuidades mecânicas que vão definir a maior ou menor estabilidade das encostas (BOTELHO, 2007). 
Os processos geomorfológicos são os múltiplos meios químicos e físicos pelos quais a superfície da Terra sofre modificações. As interações mútuas entre a forma e o processo são os principais fatores da investigação geomórfica - a forma afeta o processo e o processo afeta a forma. Em um cenário mais amplo, processos atmosféricos, processos ecológicos e processos geológicos influenciam e são influenciados por formas geomorfológicas (HUGGETT, 2011).

Apesar da resiliência inerente, o solo é propenso à degradação devido à má administração com usos agrícolas, contaminação com usos industriais e poluição com descarte de resíduos urbanos. Desse modo, o uso sustentável dos recursos do solo exige uma compreensão completa das propriedades e processos que regem a qualidade do solo (LAL e SHUKLA, 2004).

Sabe-se que o arranjo da rede de drenagem é reflexo de um conjunto de variáveis físicas como o clima, relevo, solos, substrato rochoso e vegetação. Desse modo, é possível criar considerações acerca dessas variáveis, a partir da análise criteriosa da rede hidrográfica (BOTELHO, 2007).

Por último, a cobertura vegetal da bacia é a defesa natural de um terreno contra os processos erosivos. O efeito da vegetação pode: oferecer proteção do solo contra o impacto das gotas de chuva; dispersão e interceptação das gotas d'água antes que esta atinja o solo; colaborar com a ação das raízes das plantas que formam poros e canais e que aumentam a infiltração da água; facilitar a ação da matéria orgânica que incorporada ao solo melhora sua estrutura e aumenta sua capacidade de retenção de água (BERTONI e LOMBARDI NETO, 2008).

O levantamento dos dados, em geral, vem acompanhado pela informação sobre o uso atual do solo, já que ambos estão estritamente relacionados, o que permite estabelecer as distribuições, sugestões ou alterações do uso atual podendo eleger as áreas prioritárias de implantação do planejamento ambiental (BOTELHO, 2007).

Neste contexto, a presente pesquisa teve por objetivo utilizar, principalmente, a Cartografia Temática para verificar a relação dos atributos do meio físico com o planejamento ambiental nas áreas urbana e periurbana do município de Cidade Gaúcha, Paraná, baseando-se nos produtos cartográficos existentes e elaborados para a análise.

\section{MATERIAL E MÉTODOS}

O desenvolvimento metodológico da pesquisa foi baseado em Santos (2009) e Botelho (2007). O primeiro autor aborda o uso da cartografia temática e relata que uma Macedo e Souza 2018 
abordagem geográfica na pesquisa ambiental é representada por meio de mapas, cartogramas, gráficos e tabelas produzidas a partir da utilização e interpretação de dados obtidos e tratados por sistemas informatizados ou por processos convencionais da cartografia temática e da estatística de dados geográficos. Já a segunda autora foi adotada para o levantamento dos atributos do meio físico (clima, substrato rochoso, relevo, solos, rede de drenagem e vegetação).

A presente pesquisa foi elaborada em três etapas. A primeira envolveu a revisão bibliográfica do tema, dos produtos cartográficos e da área de estudo (o material da pesquisa). A segunda e terceira etapas foram descritas no subitem Métodos do presente tópico MATERIAL E MÉTODOS e incluem as atividades em gabinete (elaboração dos produtos cartográficos e a análise do material obtido), como também, as atividades desenvolvidas em campo.

\section{MATERIAL}

A área de estudo localiza-se nas coordenadas geográficas de $23^{\circ} 22^{\prime} 49^{\prime \prime}$ de latitude $\mathrm{S}$ e 52 $56^{\prime} 11^{\prime \prime}$ de longitude W e altitude 404 metros, no município de Cidade Gaúcha, região Noroeste do estado do Paraná. (Figura 1). O município possuí uma população estimada em 2016 de 12.199 habitantes numa área de $403 \mathrm{~km}^{2}$ (IPARDES, 2016).

A caracterização geográfica no contexto regional da área de estudo mostrou que o município de Cidade Gaúcha encontra em sua totalidade no Terceiro Planalto Paranaense e no Planalto de Campo Mourão, descritos por Maack (2012).

O substrato rochoso da área estudada está inserido na Bacia Sedimentar do Paraná composta por rochas areníticas da Formação Caiuá (MINEROPAR, 2006). Os solos predominantes na região, segundo Santos et al. (2008) são: Latossolos Vermelhos e Argissolos Vermelhos.

A área de estudo está inserida regionalmente na bacia hidrográfica do rio Ivaí e os principais cursos d'água são: Córrego Apoeira, Ipiranga, Palmital e Minuano; Ribeirão Talogan e Rio Itaoca. Bigarella e Mazuchowski (1985) relatam que a vegetação natural dominante era da Floresta Tropical Semidecidual da Bacia Sedimentar do Paraná. Segundo a classificação de Köppen (1948), o clima que predomina na região é do tipo Cfa subtropical úmido mesotérmico.

Em termos econômicos, segundo IPARDES (2016), em 2013, as indústrias de produtos alimentícios, de bebida, e álcool etílico abrangeram $64 \%$ do total de empregos no município, enquanto o setor agropecuário representado pela agricultura, silvicultura, 
Figura 1 - Localização do município de Cidade Gaúcha
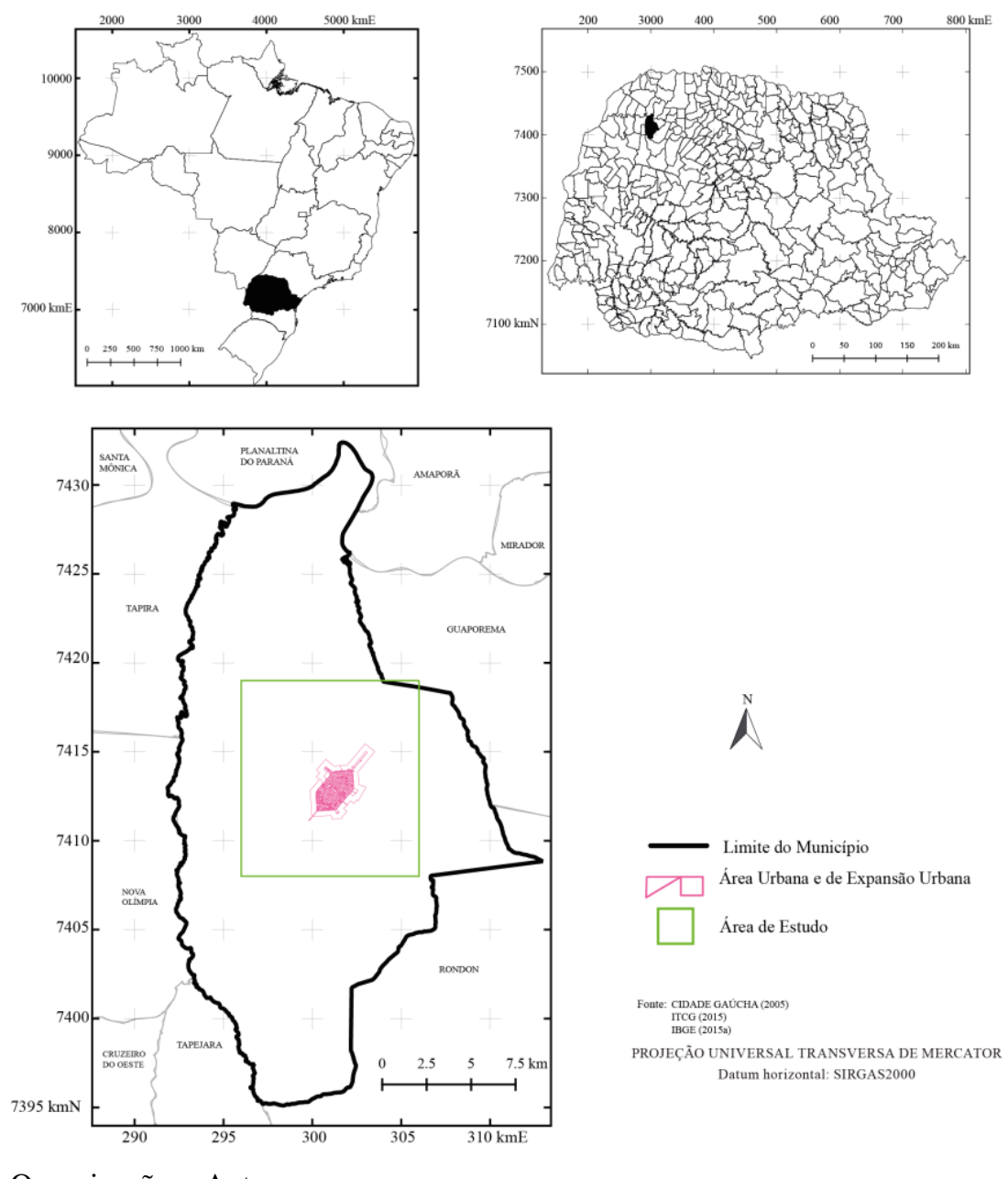

PROJEÇÃO UNIVERSAL TRANSVERSA DE MERCATOR

criação de animais, extração vegetal e pesca contou $5 \%$ do total de empregos. Apesar dos dados do Censo Agropecuário de 2006 (IBGE, 2015b) apontarem que a área destinada a pecuária e a criação de outros animais foi de 25.175 hectares, sendo essa a maior atividade em área territorial no município, porém os dados demonstram que a cana-de-açúcar é a atividade mais importante no município.

\section{MÉTODOS}

Nesta pesquisa a base cartográfica foi elaborada da folha topográfica SF-22-Y-C-III3 de Rondon, PR (DSG., 1989) na escala de 1:50.000. A área de estudo compreende as latitudes 7419 kmN; 7408 kmN e longitudes 296 kmE; 306 kmE, no Sistema de Projeção UTM. As cartas e os gráficos foram elaborados no Sistema Operacional Microsoft Windows $10 \circledR$ versão 1607 de 64 bits e finalizadas no software Adobe Illustrator CC®. 
Os dados climatológicos foram obtidos, por meio de informações do Instituto das Águas do Paraná (ÁGUASPARANÁ, 2015), sendo os dados de precipitações pluviométricas anuais, mensais e diárias entre $1^{\circ}$ de janeiro de 1976 até 31 de dezembro de 2014.

As informações geológicas da área pesquisada foram extraídas do mapa geológico do estado do Paraná produzido pela MINEROPAR (2006) e checados em campo, por meio de rochas expostas nos leitos dos córregos e nos cortes de estradas.

Em função da escala original da pesquisa, 1:50.000, não foi realizada uma avaliação detalhada da rede de drenagem, devido a esta escala não permitir uma visualização adequada dos cursos d'água. A área de estudo está inserida numa bacia hidrográfica de segunda ordem na classificação de Strahler (1952) apud Christofoletti (1980). Além disso, para a elaboração da carta de uso da terra de 2014, utilizou-se a metodologia do IBGE (2013).

A carta clinográfica (declividade) foi adaptada de Macedo e Souza (2014), que estudaram o mesmo recorte espacial, no qual teve como base a metodologia de De Biasi (1992).

Na elaboração do Modelo Digital de Terreno (MDT) utilizou-se as curvas de nível da base cartográfica previamente digitalizadas e configuradas no Autodesk AutoCAD Civil 3D $2017 ®$ onde foram inseridos os valores altimétricos de cada curva. O arquivo . $d x f$ foi exportado para programa Golden Software Surfer $13{ }^{\circledR}$ onde foi gerado um grid que possibilitou a elaboração do modelo 3D e o direcionamento do fluxo hídrico superficial. Essa elaboração teve como base os trabalhos de Melo et al. (2015) e Coelho Júnior (2015). As cores foram adotadas de Libault (1975), ou seja, as mesmas propostas na elaboração de uma carta hipsométrica.

Não foi possível utilizar a carta pedológica do Paraná proposta por Santos et al. (2008), devido a escala de produção da carta ser de 1:250.000, desde modo, a carta de solos, desta pesquisa, derivou da Carta de Zonas de Riscos à Erosão de Cidade Gaúcha, produzida em escala 1:25.000, do convênio realizado, no início da década de 1990, entre a Universidade Estadual de Maringá, o Departamento de Geografia (UEM/DGE) e a Superintendência do Controle da Erosão e Saneamento Ambiental (SUCEAM). Outros elementos morfopedológicos foram inseridos como o direcionamento de vertentes, nascentes degradadas, pisoteio de gado, ravinas e voçorocas baseados na carta morfopedológica de Nakashima (1999).

A escolha dos locais para a elaboração dos perfis geoecológicos ocorreu em função da melhor representatividade do relevo nas áreas urbana e periurbana. Realizou-se dois perfis, 
o perfil A-B, no sentido noroeste/sudeste e o perfil C-D, no sentido nordeste/sudoeste, ambos elaborados na escala de 1:50.000 com exagero vertical de cinco vezes.

\section{RESULTADOS E DISCUSSÕES}

Os atributos do meio físico na área de estudo foram explicitados em documentos cartográficos e são descritos na sequência. No atributo do clima, conforme a descrição geral da área o clima Cfa subtropical úmido mesotérmico, é caracterizado por apresentar verões quentes e geadas poucos frequentes com tendência a concentração das chuvas nos meses de verão, sem estação seca definida. A média das temperaturas nos meses quentes é acima de 22 ${ }^{\circ} \mathrm{C}$, e a média das mínimas $18^{\circ} \mathrm{C}$ (SILVEIRA, 1997). A pluviosidade média no município é de $1480 \mathrm{~mm}$ e os meses mais chuvosos vão de outubro a fevereiro, com médias mensais de 160 $\mathrm{mm}$. Os meses de julho e agosto são os meses mais secos, com médias de $62 \mathrm{~mm}$ (ÁGUASPARANÁ, 2015).

Nas Figuras 2 e 3 podem ser observados os dados separados em médias mensais e o total anual, da área estudada, respectivamente, no período de 1976 a 2014. Os dados revelam que a época do verão (azul) é a mais chuvosa no período estudado com média de $154 \mathrm{~mm}$ seguido pela primavera (verde) com $153 \mathrm{~mm}$ de média; período menos chuvoso é o inverno (vermelho) com apenas $81 \mathrm{~mm}$ de média. Essa média do inverno ainda foi influenciada pelos dados de setembro com $118 \mathrm{~mm}$ de média total, contra $64 \mathrm{~mm}$ de média e $61 \mathrm{~mm}$ de média dos meses de julho e agosto, respectivamente.

Figura 2 - Precipitação média mensal no período de 1976-2014, Cidade Gaúcha, PR

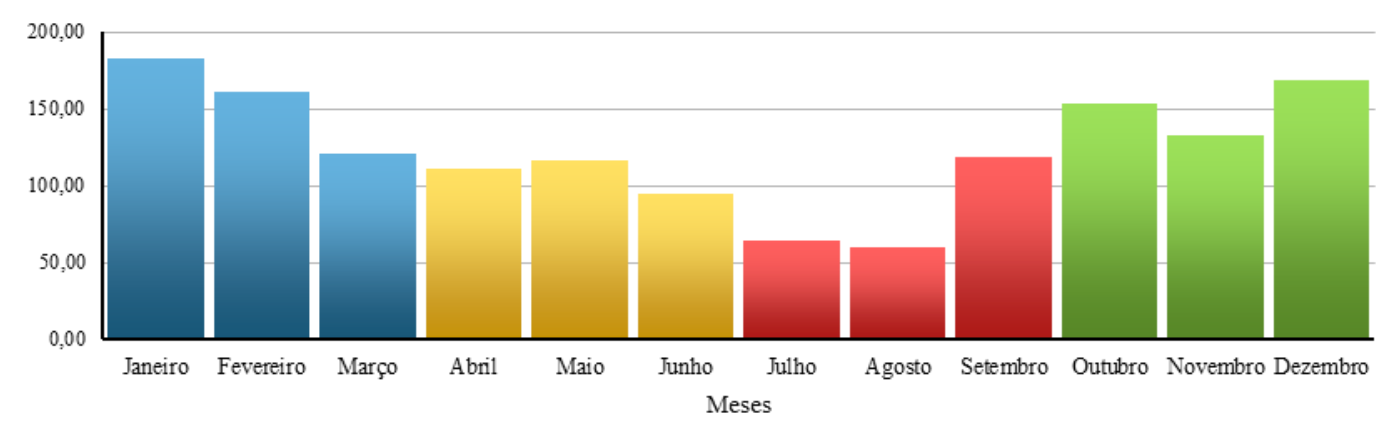

Elaboração - Felipe R. Macedo Fonte - AGUASPARANÁ (2015) 
Figura 3 - Precipitação total anual (mm) no período de 1976 - 2014, Cidade Gaúcha

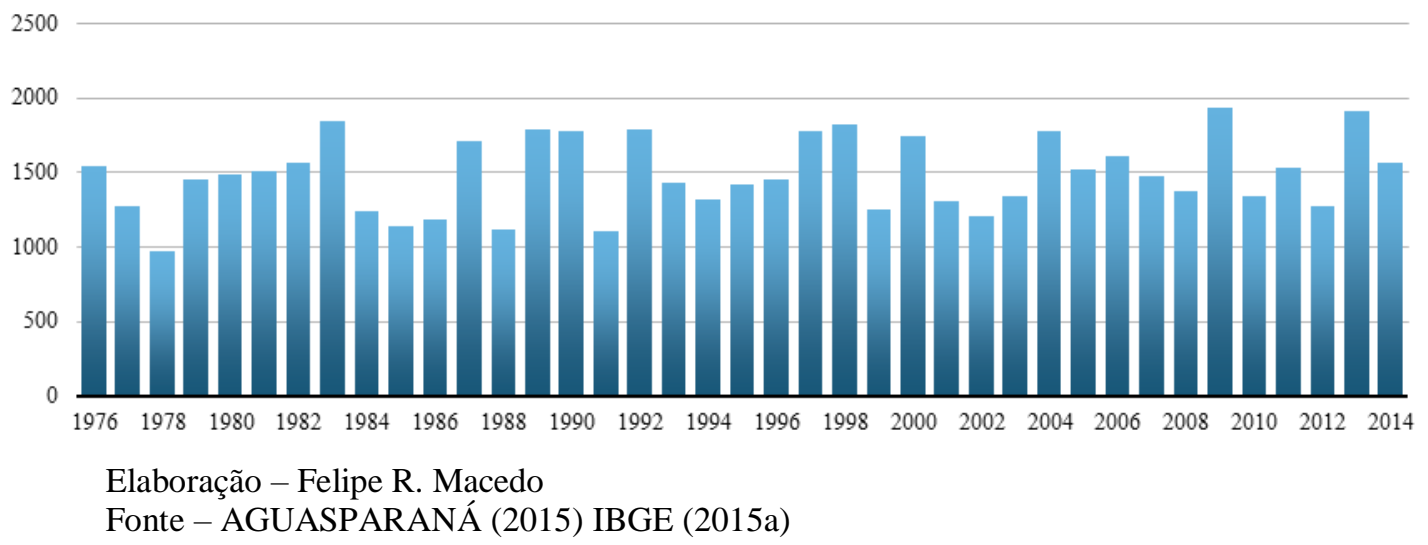

Neste contexto, Prado e Nóbrega (2005) estudaram a bacia do córrego Ipiranga, utilizando o modelo para o cálculo da EUPS. Eles apontaram que a erosividade da chuva foi calculada por meio de médias pluviométricas mensais, sazonais e anuais correspondentes, a uma série de dados de 27 anos. Os resultados apontaram que as perdas de solos predominaram na primavera e não no verão (estação mais chuvosa), porém os cultivos ocorrem na primavera, assim, no verão, o solo possui algum tipo de proteção que ajuda contra a erosão.

No levantamento do atributo substrato rochoso foi identificado que no município de Cidade Gaúcha, a litologia predominante é a Formação Caiuá do Grupo Bauru, descrita por Soares et al. (1980). A Formação Caiuá é composta por arenitos finos a médios, com frações muito finas, e grossa subordinadas, bem selecionados por lâminas, com pouca matriz argilosa e cor marrom-arroxeado a avermelhado (FERNANDES, 1992).

Quanto aos aspectos do atributo solos no município de Cidade Gaúcha, segundo Nóbrega et al. (2003) foram mapeados como Latossolo Vermelho, textura média-arenosa em posições de topo e alta vertente e Argissolo Vermelho textura média-argilosa normalmente ocorre em relevo de vertentes convexas de declividades ligeiramente acentuadas, principalmente, em posições de média-baixa vertente.

Segundo os autores ocorre uma transição entre os Latossolos e os Argissolos nos setores de média vertente mapeados como Associação Argissolo Vermelho/Latossolo Vermelho. Os outros solos encontrados, na área de estudo, em alguns setores de baixa vertente foram denominados como Solos Rasos, representados por Neossolos Litólicos e os Cambissolos e junto às margens dos ribeirões e córregos podem ocorrer manchas esparsas de Gleissolos. Os materiais inconsolidados gerados e depositados depois do desmatamento da região Noroeste do Paraná, normalmente foram encontrados em vales em berço e cabeceiras de drenagem e foram mapeados como Solos Coluviais. 
Na Figura 4 pode ser observada a carta clinográfica ou de declividade, o tipo de relevo predominante na área é o suave ondulado $\left(1,72^{\circ}-4,57^{\circ}\right)$, localizado no topo e, principalmente, na alta vertente, chegando em alguns locais à média vertente. Esse tipo de relevo abrange quase a totalidade da área analisada, em especial a área rural, com a predominância do Latossolo Vermelho, podendo atingir, nas áreas de média vertente, a Associação Argissolo/Latossolo. Na área urbana predomina o relevo plano $\left(0-1,72^{\circ}\right)$ e os Latossolos Vermelhos.

Figura 4 - Carta Clinográfica de Cidade Gaúcha - PR

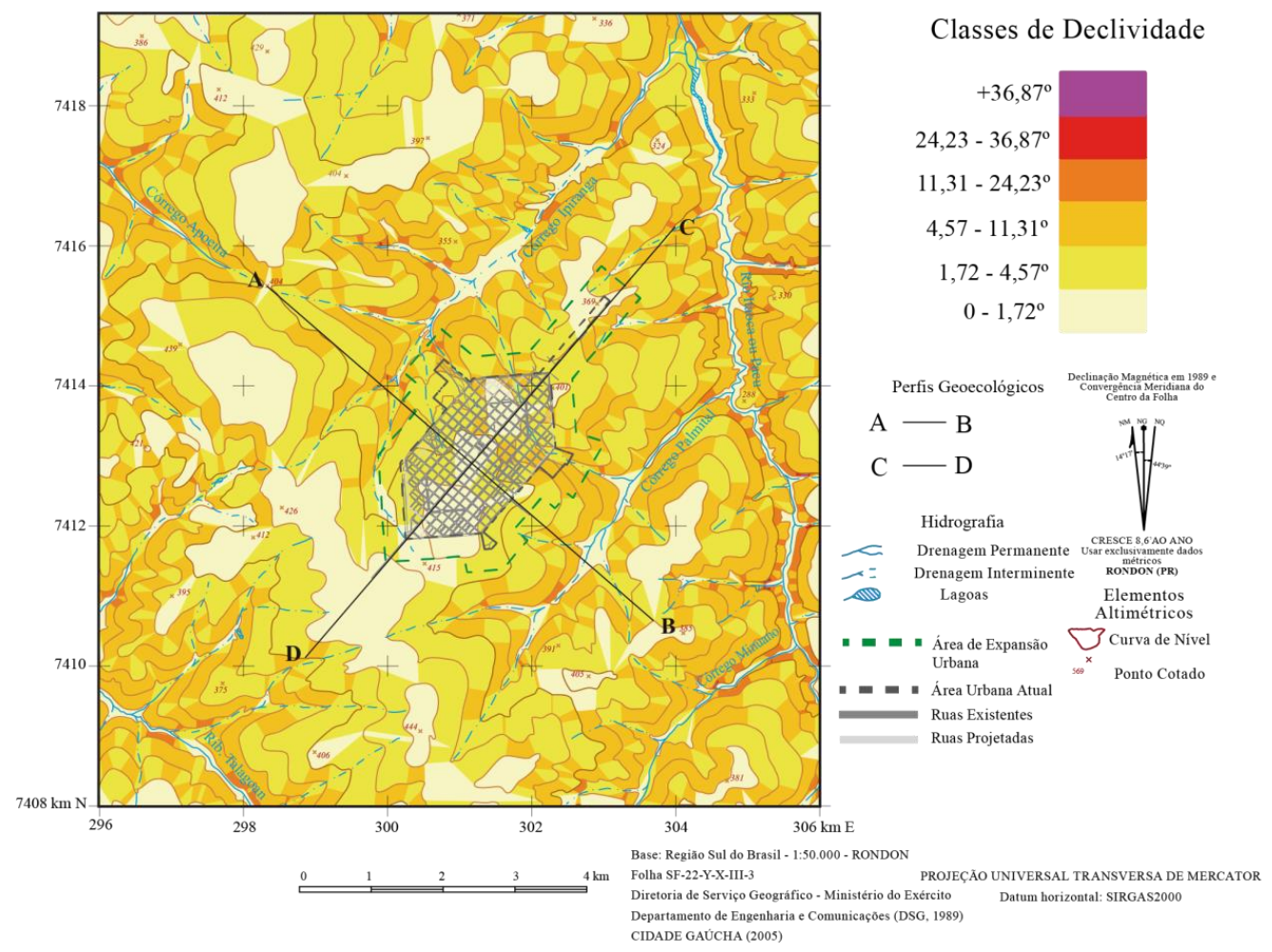

Adaptado - Macedo e Souza (2014)

O Modelo Digital de Terreno (Figura 5) apresenta a suavidade do relevo e as relações altimétricas variando de 280 até 440 metros, como também, o direcionamento dos fluxos das águas pluviais no relevo original, ou seja, sem a interferência da área urbana. Ao analisar o modelo percebe-se que a voçoroca localizada no setor norte da área urbana, não possui um direcionamento específico das águas pluviais naquela área, ou seja, os direcionamentos são relativamente iguais em toda a área, assim este pode ser um indicativo que a voçoroca originou-se da instalação do sistema de drenagem deficitário da área urbana, como apontado por Macedo e Souza (2016). 
Figura 5 - Modelo Digital de Terreno de Cidade Gaúcha, PR (Elaboração: Autores).

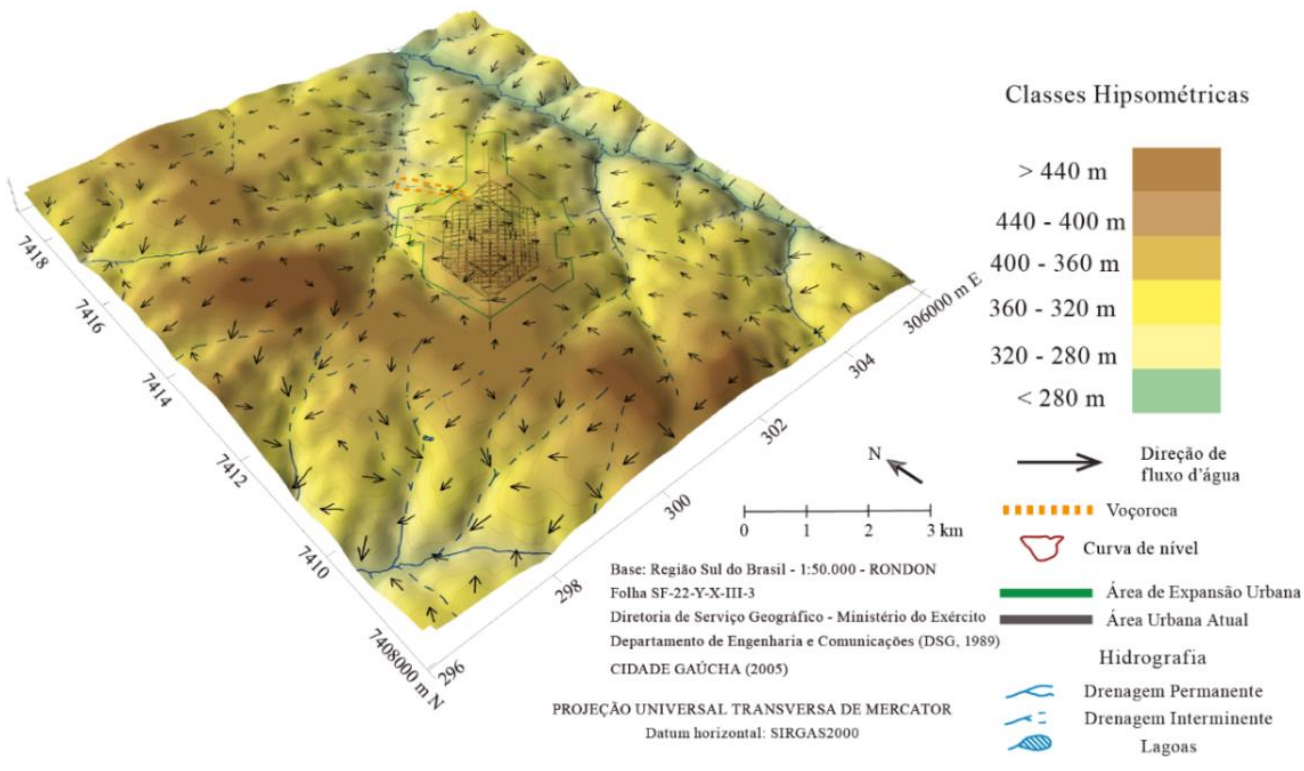

A carta morfopedológica (Figura 6) teve como base a carta realizada por Nakashima (1999), que verificou que a área pertence a dois compartimentos morfopedológicos. A compartimentação morfopedológica 1 possui relevo menos dissecado com colinas amplas e médias, topos planos ligeiramente convexizados, as vertentes são convexas-retilíneas; 600 a $1500 \mathrm{~m}$ de comprimento. Declividades média de $1,15^{\circ}$ a $2,86^{\circ}$ (2\% a 5\%) nas altas e médias vertentes; $4^{\circ}$ a $5,7^{\circ}$ (7 a 10\%) nas baixas vertentes e vales pouco entalhados e " $U$ " abrangendo os setores norte, oeste e sudoeste da carta.

A compartimentação morfopedológica 2 possui relevo mais dissecado, com colinas amplas e médias topos ligeiramente convexizados e as vertentes são convexas-retilíneas; 500 a $1000 \mathrm{~m}$ de comprimento e declividades de $2,86^{\circ}$ a $4^{\circ}$ (5 a 7\%) nas altas e médias vertentes; vale pouco entalhados em " $U$ " nas cabeceiras das nascentes e "V" no médio curso da rede de drenagem. Está situada a leste e sudeste da carta tendo como limite o Córrego Palmital.

Devido a escala utilizada, nesta pesquisa, não foi possível detalhar os mesmos elementos morfológicos que Nakashima (1999). Os elementos cartografáveis foram ravinas e voçorocas, pisoteio de gado e nascentes degradadas. O pisoteio de gado que ocorre na área é localizado apenas nos pastos que estão em atividade sendo que as outras áreas utilizadas estão em recuperação dos pastos e, desse modo, elas não apresentam o pisoteio o que indica a rotatividade do gado. 
Figura 6 - Carta morfopedológica de Cidade Gaúcha, PR

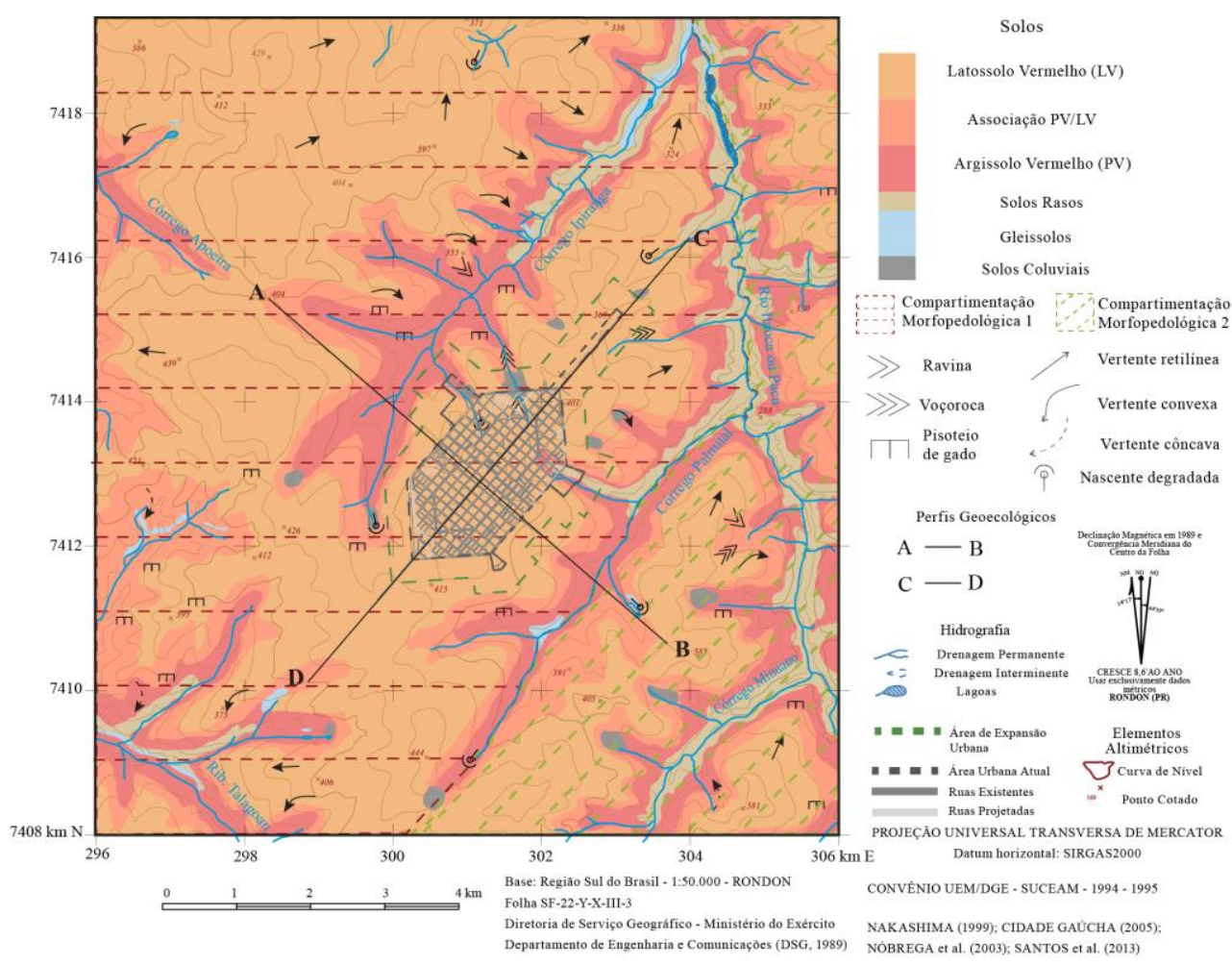

Adaptação - Autores

Figura 7 - Carta de uso da terra em 2014 de Cidade Gaúcha, PR

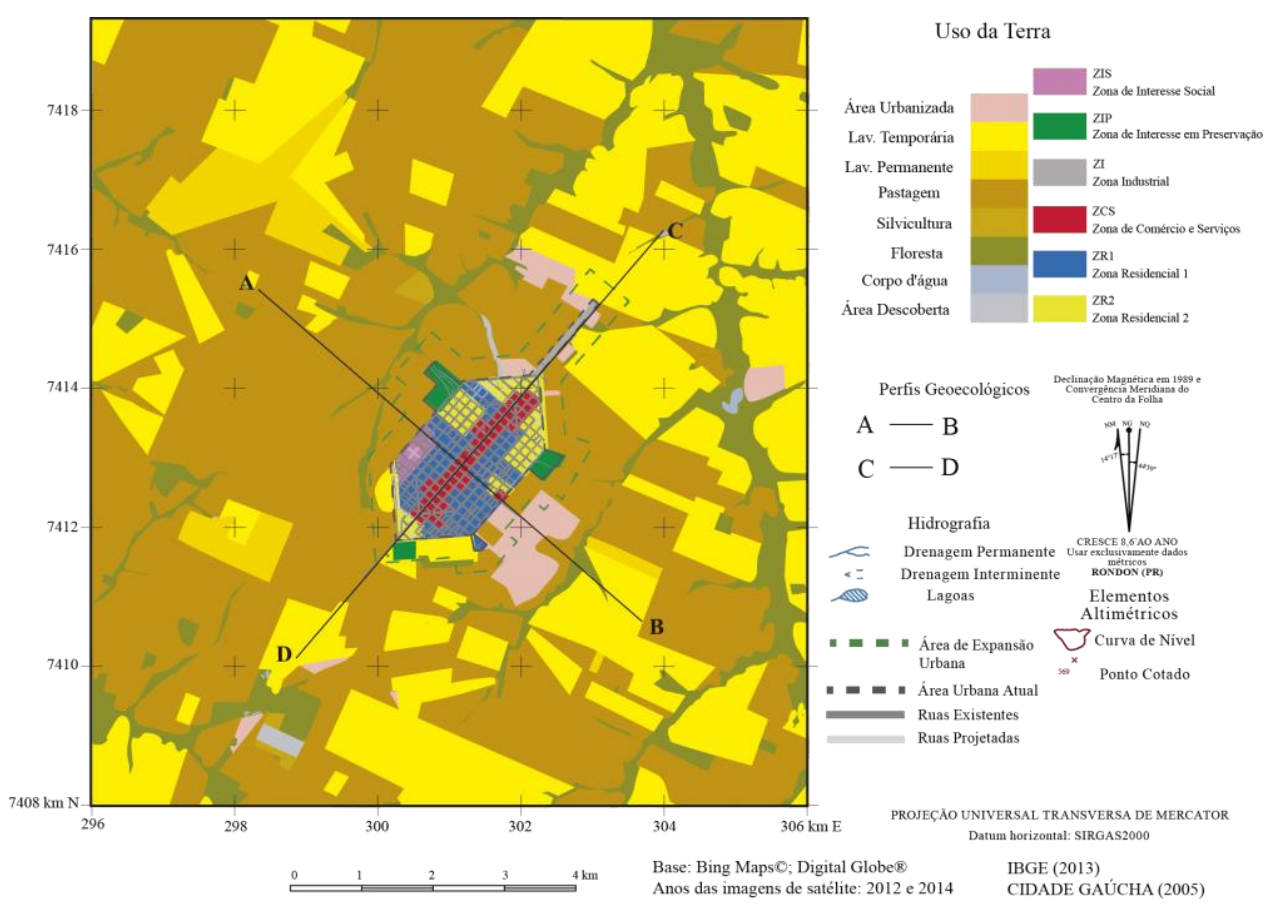

Na carta de Uso da Terra de 2014 (Figura 7) foram identificadas oito classes na área de estudo descritas a seguir: 
a) Áreas urbanizadas - além da infraestrutura urbana compreende, também, a Vila Rural Fiorêncio Baréa; indústrias localizadas fora da zona industrial; a USAÇÚCAR (Usina Santa Teresinha) e o Campus do Arenito da Universidade Estadual de Maringá (CAR/UEM), correspondendo a $5 \%$.

b) Lavoura Temporária - na área de estudo é o segundo maior uso com 30\%, predominando o cultivo de cana-de-açúcar.

c) Lavoura Permanente - correspondem a $4 \%$ da área de estudo, predominando o cultivo de laranja.

d) Pastagem - essa atividade é a que ocupa a maior parte da área de estudo com $49 \%$.

e) Silvicultura - na área de estudo apresentam $1 \%$ do total.

f) Floresta - foram incluídas as matas nativas, ciliares, de reflorestamento representando $10 \%$ da área de estudo.

g) Corpo d'água - na área de estudo foram considerados apenas os lagos das indústrias, pesqueiros e lagos naturais $0,5 \%$.

h) Área descoberta - compreende a $0,5 \%$ do total sendo as áreas com feições erosivas que estão localizadas, principalmente, no setor norte da área urbana.

A carta de uso da terra de 2014, também apresenta o Zoneamento Urbano de Cidade Gaúcha (CIDADE GAÚCHA, 2005), dividido em seis zonas, além da zona de expansão urbana, que corresponde a uma faixa de 300 metros de largura, localizada na área perirubana que fica entre as zonas urbana e a rural.

a) Zona de Interesse Social (ZIS) - destinada ao desenvolvimento de assentamentos urbanos vinculados a programas habitacionais de interesse social ou programas de regularização fundiária de iniciativa pública ou privada, na forma estabelecida em lei. Essas áreas podem ser implantadas em qualquer parte da área urbana, exceto a Zona de Comércio e Serviços;

b) Zona de Interesse em Preservação (ZIP) - compreende as áreas sujeitas às inundações, erosão e com cobertura arbórea significativa, onde deve ocorrer a implantação de parques lineares, destinados às atividades de recreação e lazer, à proteção de matas ciliares, para facilitar a drenagem urbana e a preservar áreas críticas;

c) Zona Industrial (ZI) - predominância de atividades industriais, bem como das atividades complementares compreendidas ao longo da PR-082, sentido norte;

d) Zona de Comércio e Serviços (ZCS) - corresponde aos estabelecimentos comerciais, associações, sindicatos, templos religiosos dentre outros; 
e) Zona Residencial 1 (ZR1) - predominantemente destinada à implantação de moradias unifamiliares, habitação coletiva e atividade comercial e de serviços;

f) Zona Residencial 2 (ZR2) - destinada ao uso habitacional e atividade comercial.

Os perfis geoecológicos agruparam o mesmo substrato rochoso (arenitos da Formação Caiuá), os diferentes tipos de solos e os usos da terra. No perfil A-B (Figura 8) pode ser observado o relevo plano e suave ondulado no topo, na alta e na média vertente na bacia do córrego Ipiranga. Nessa área predomina as pastagens com as ocorrências de fragmentos florestais degradados apenas junto aos cursos d'água. A área urbana atual está entre as duas bacias, córregos Ipiranga e Palmital. A zona de expansão urbana, na bacia do córrego Ipiranga se mantém em área de relevo suave ondulado, com Latossolo Vermelho e sendo uma área própria para ocupação da cidade com o controle do escoamento superficial como apontado por Nóbrega et al. (2003). O mesmo ocorre na bacia do córrego Palmital, porém esse possui uma quebra no relevo, onde ocorre a transição para a compartimentação morfopedológica 2 onde a vertente da margem direita é mais curta que na margem esquerda (Figura 9).

Figura 8 - Perfil A-B

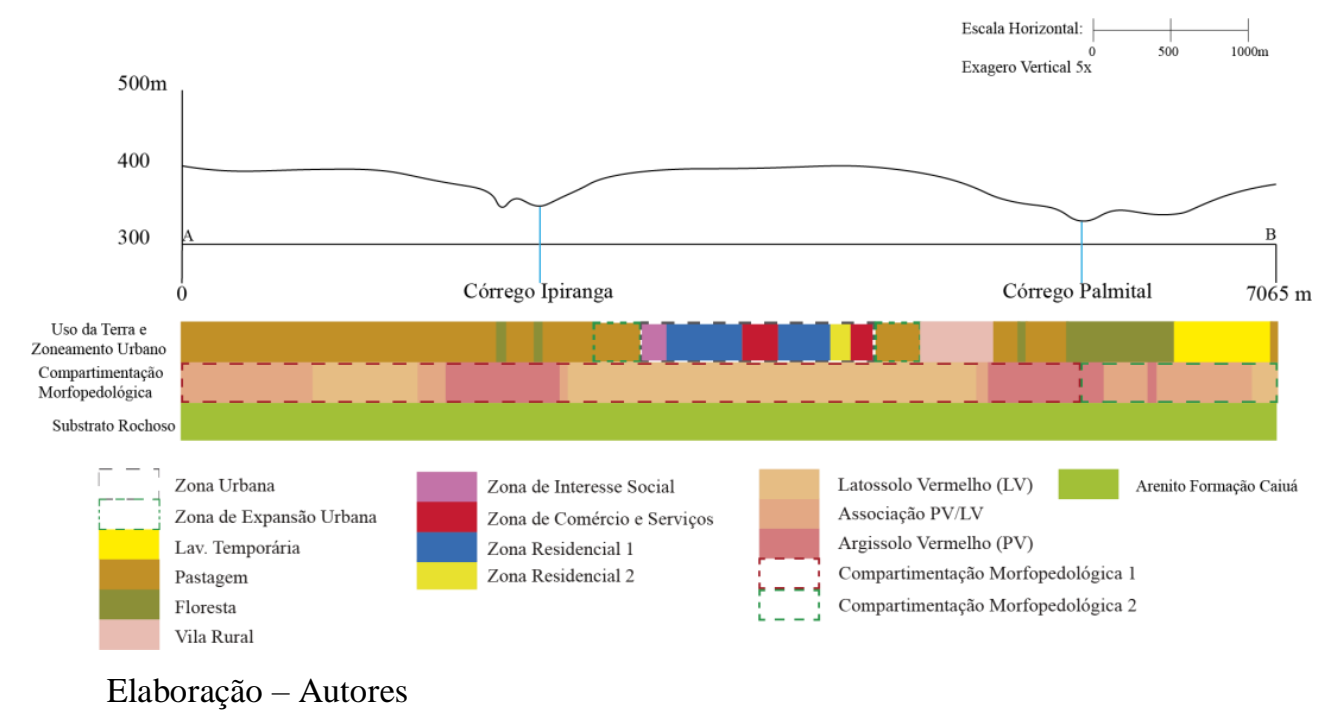


Figura 9 - Vista da vertente direita para vertente esquerda do córrego Palmital

Elaboração - Autores

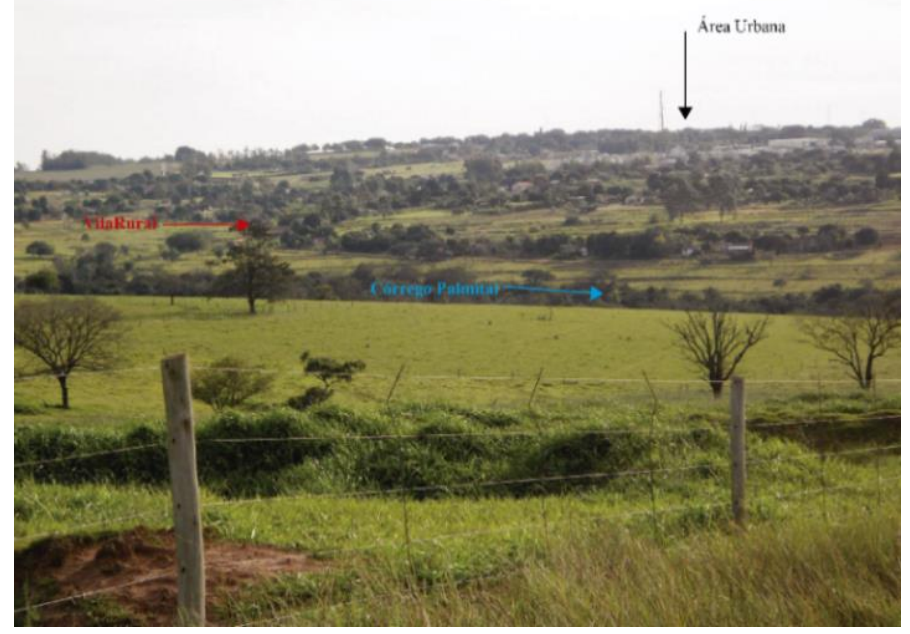

Foto - Ricardo H. Bueno

Figura 10 - Perfil C-D

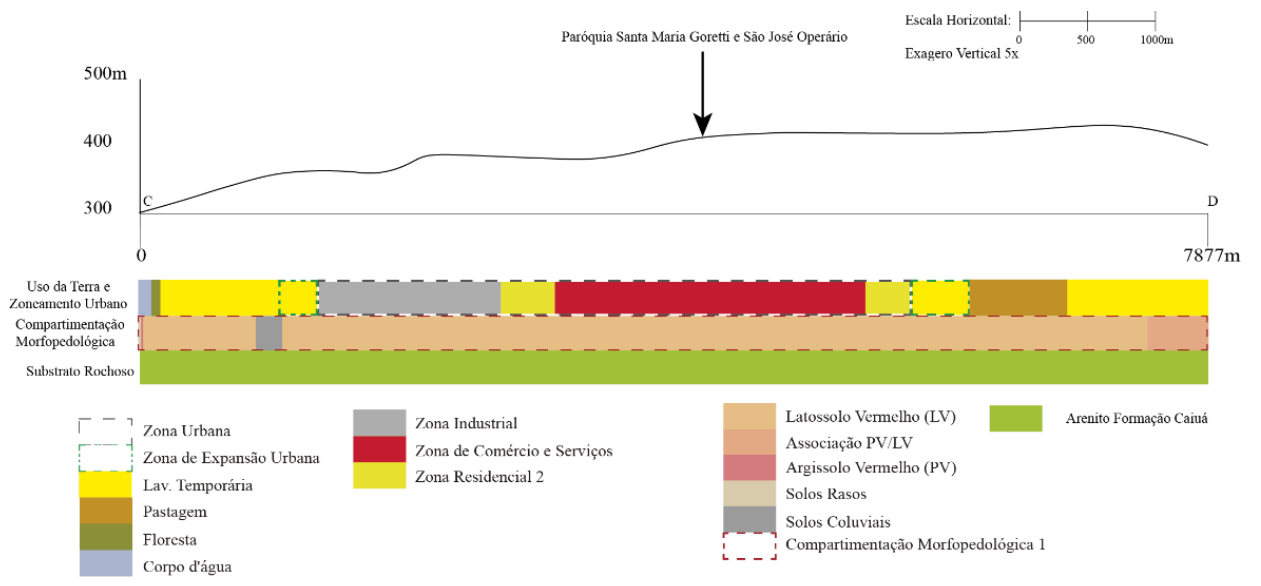

Elaboração - Autores

O perfil C-D, nordeste/sudoeste (Figura 10), foi delimitado ao longo das Avenidas Comendador Gentil Geraldi e Antonio Tormena. Apenas no início do perfil, próximo ao tributário do rio Itaoca é possível encontrar Solos Rasos e Argissolos, nas outras áreas predominam Latossolos Vermelhos, o que pode gerar áreas estáveis recomendadas à ocupação, com o controle de escoamento superficial. Quanto ao Uso da Terra, além da área urbana, predominam as lavouras temporárias, em grande parte pelo cultivo de cana-de-açúcar.

Os primeiros 1300 metros da área urbana, na Avenida Comendador Gentil Geraldi (Figura 11), correspondem a Zona Industrial, na sequência a Zona Residencial 2 e a Zona Comercial. Esta é a região de maior adensamento populacional. A 4100 metros do início do perfil encontra-se a Paróquia Santa Maria Goretti e São José Operário, acima dos 420 metros de altitude, no ponto mais alto da área urbana. Depois da paróquia a Avenida passa a se chamar Antonio Tormena até o fim do perímetro urbano, onde a avenida retorna à Macedo e Souza 2018 ISSN 0104-5490 
denominação de rodovia PR-082. Essa área, periurbana, com relevo plano a suave ondulado, presença de Latossolos e ocupação por pastagens é indicada para a ocupação urbana.

A análise dos atributos do meio físico identificou na área pesquisada que existe uma susceptibilidade natural para a ocorrência de processos erosivos que se originam do substrato rochoso (arenitos) e da cobertura pedológica, com solos de textura média que foram potencializados pelo desmatamento ocorrido na ocupação da área, a partir dos anos de 1940 e que propiciou o desenvolvimento de sulcos, ravinas e voçorocas, além das feições erosivas contribuírem para o assoreamento nos cursos d'água. Deste modo, os mapeamentos realizados em gabinete e campo mostraram que existe uma necessidade de planejamento ambiental para a recuperação, preservação e conservação de florestas e matas ciliares, de acordo com a legislação vigente para um planejamento consciente na expansão da ocupação tanto na área urbana como na periurbana.

Figura 11 - Vista parcial da avenida Comendador Gentil Geraldi em frente a Paróquia

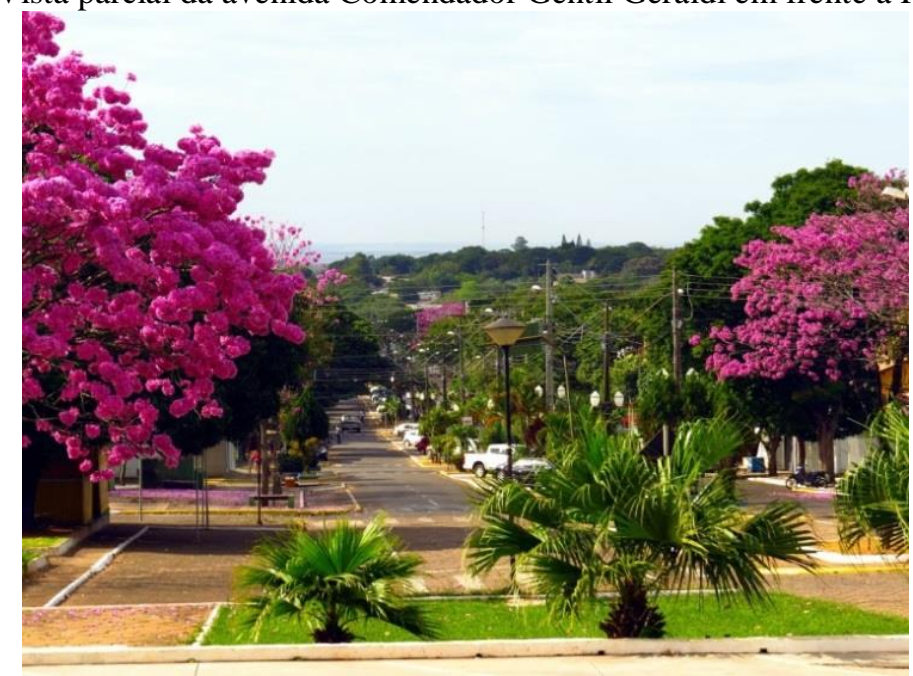

Fonte - Panoramio (2013)

Foto - Ricardo Mercadante

\section{CONSIDERAÇÕES FINAIS}

Neste artigo foram apresentadas as cartas temáticas dos atributos do meio físico da área urbana e periurbana do município de Cidade Gaúcha, além dos gráficos com dados climáticos e perfis geoecológicos. Dentre esses produtos, destacamos a carta clinográfica que mostrou o relevo pouco dissecado da região, onde predomina a classe suave ondulado. As vertentes tendem a serem planas no topo, suave ondulado na média vertente, ondulado na baixa e, em alguns casos, forte ondulado próximo ao corpo hídrico.

O modelo digital de terreno contribuiu com a carta clinográfica no que tange a apresentação do relevo em três dimensões com amplitude altimétrica de 280 a 440m. A carta 
de uso do solo de 2014 mostrou que a pastagem predomina na região junto com a cana-deaçúcar que é a atividade mais rentável do município.

A carta morfopedológica apresentou os tipos de solos sendo: o Latossolo Vermelho, Associação Argissolo/Latossolo e Argissolo Vermelho os predominantes na área. Esses solos, de maneira geral, são de textura média-arenosa o que se caracteriza como uma das causas do desenvolvimento das feições erosivas na área de estudo aliada ao sistema deficitário do escoamento das águas pluviais da área urbana.

Esta carta mostrou, também, os dois compartimentos que existem no local de estudo, sendo que a leste da carta o relevo é mais dissecado pelo fato de ter o córrego Palmital como limite. Essa característica também foi vista no perfil geoecológico A-B, que abrangeu as bacias dos Córregos Ipiranga e Palmital cortando a área urbana e de expansão urbana onde as vertentes do córrego Ipiranga possuem maior comprimento e o relevo menos dissecado até a margem esquerda do Córrego Palmital.

O perfil geoecológico C-D no sentido noroeste/sudoeste apresentou o relevo da rodovia PR-082 e em toda sua extensão da área urbana desde o setor industrial, residencial, comercial, o centro da cidade e a paróquia, no ponto mais alto da área urbana em 420 metros ao outro setor residencial e, terminando o perímetro urbano em uma área plana mantendo a altitude de 420 metros.

Em relação ao levantamento dos dados cartográficos a escala, que nem sempre compatível, não permitiu a utilização completa de alguns deles, como por exemplo, a carta de solos da EMBRAPA disponível na escala, 1:250.000 que não possuía um detalhamento dos tipos de solos. No caso da carta morfopedológica, a escala de 1:25.000, apresentou muito mais dados que daqueles que seriam visualizados na escala de 1:50.000.

Como dito anteriormente, o relevo do município de Cidade Gaúcha não é o principal atributo do meio físico em relação ao desenvolvimento das feições erosivas, ficando a cargo da susceptibilidade dos solos e substrato rochoso. Deve ser considerado, também, que uma infraestrutura instalada de maneira incorreta para o escoamento das águas pluviais em áreas urbanas pode piorar essa característica natural. Todos os produtos cartográficos (cartas temáticas, gráficos e perfis) mostraram a contribuição que os mapeamentos dos atributos do meio físico podem fornecer para o planejamento ambiental da área pesquisada. Infelizmente, nem todos os municípios brasileiros possuem esses dados cartográficos básicos, que auxiliaram na elaboração das cartas temáticas, disponíveis em escalas adequadas, sendo que eles subsidiariam o planejamento ambiental e a gestão do território para uma interação equilibrada. 


\section{REFERÊNCIAS}

ÁGUASPARANÁ. Instituto das Águas do Paraná Sistemas de informações hidrológicas Curitiba, 2015. Disponível em: 〈http://www.aguasparana.pr.gov.br>. Acesso em 16 de janeiro de 2015.

BERTONI, J.; LOMBARDI NETO, F. Conservação do Solo. 6. ed. São Paulo: Ícone, 2008. $355 \mathrm{p}$.

BIGARELLA, J. J.; MAZUCHOWSKI, J. Z. Visão Integrada da problemática da erosão. Curitiba: Associação de Defesa e Educação Ambiental e Associação Brasileira de Geologia de Engenharia, 1985. 329 p.

BOTELHO, R. G. M. Planejamento ambiental em microbacia hidrográfica. In: GUERRA, A. J. T.;SILVA, A. S. e BOTELHO, R. G. M. (Org.). Erosão e conservação dos solos, temas e aplicações. 3. ed. Rio de Janeiro: Bertrand Brasil, 2007. p. 269-300.

CHRISTOFOLETTI, A. Geomorfologia. 2. ed. São Paulo: Edgard Blucher, 1980. 188 p.

CIDADE GAÚCHA. Lei 1.636/2005 Zoneamento, uso e ocupação do solo. Cidade Gaúcha: 2005.

COELHO JÚNIOR, J. M. Modelo digital do terreno através de diferentes interpolações do programa surfer 12. Revista GEAMA, Recife, v. 1, n. 1, p. 70-83, 2015.

DE BIASI, M. Carta clinográfica: Os métodos de representação e sua confecção. Revista do Departamento de Geografia, São Paulo, v. 6, p. 45-60, 1992.

DSG. Diretoria de Serviço Geográfico Região Sul do Brasil Rondon Folha SF-22-Y-C-III-3. Brasília: DSG, 1989. 1 mapa, Escala 1:50000.

FERNANDES, L. A. A cobertura pedológica cretácea suprabasáltica no Paraná e Pontal do Paranapanema (SP): os grupos Bauru e Caiuá. 1992. 188 f, Dissertação (Mestrado em Geologia Sedimentar)-Instituto de Geociências, Universidade de São Paulo, São Paulo, 1992.

HUGGETT, R. J. Fundamentals of Geomorphology. 3th ed. London: Routledge, 2011. 533 p.

IBGE. Manual técnico de uso da terra. 3. ed. Rio de Janeiro: IBGE, 2013. 171 p.

IBGE. Base Continua 1:250.000 - BC250. Rio de Janeiro: IBGE, 2015a. 32 p.

IBGE. Instituto Brasileiro de Geografia e Estatística Sistema IBGE de recuperação automática - SIDRA Brasília, 2015b. Disponível em: <http://www.sidra.ibge.gov.br/bda/default.asp>. Acesso em 15 de janeiro de 2015.

IPARDES. Caderno estatístico: município de Cidade Gaúcha. Curitiba: IPARDES, 2016. 41 p. 
ITCG. Instituto de Terras, Cartografias e Geociências Dados geoespaciais de Referência, 2015. Disponível em: <http://www.itcg.pr.gov.br/modules/faq/category.php?categoryid=8\#>. Acesso em 05 de Agosto de 2015.

KÖPPEN, W. Climatologia: con un estudio de los climas de la Tierra. Mexico: Fondo de Cultura Económica, 1948. 478 p.

LAL, R.; SHUKLA, M. K. Principles of soil physics. New York: Marcel Dekker, 2004. 699 p.

LEPSCH, I. F. 19 Lições de Pedologia. São Paulo: Oficina de Textos, 2011. 456 p.

LIBAULT, A. Geocartografia. São Paulo: Ed. Nacional, EDUSP, 1975. 387 p.

MAACK, R. Geografia física do estado do Paraná. 4. ed. Ponta Grossa: Editora UEPG, 2012. $526 \mathrm{p}$.

MACEDO, F. R.; SOUZA, M. L. O Uso do iPad na elaboração de cartas clinográficas. In: VI Congresso Ibero-americano de Estudos Territorias e Ambientais (CIETA). VI, 2014, São Paulo, Anais. São Paulo, 2014. p. 4898-4916.

MACEDO, F. R.; SOUZA, M. L. D. Ocupação das zonas de vulnerabilidade à erosão em Cidade Gaúcha - Paraná. Formação (online), Presidente Prudente, v. 2, n. 23, p. 230-251, 2016.

MELO, F. P., et al. Mapeamento do fluxo hídrico superficial da área de proteção ambiental do morro do urubu. In: VIII Encontro de recursos hídricos em Sergipe. 2015, Aracaju, Anais... Aracaju: Embrapa, 2015. p. 107-116.

MINEROPAR. Minerais do Paraná S/A Mapa Geológico do Paraná. Curitiba: MINEROPAR, 2006. 1 mapa, Escala 1:250000.

NAKASHIMA, P. Sistemas pedológicos da região noroeste do estado do Paraná: Distribuição e subsídios para o controle da erosão. VOL I e II. 1999. 237 f, Tese (Doutorado em Geografia)-Faculdade de Filosofia, Letras e Ciências Humanas, Universidade de São Paulo, São Paulo, 1999.

NÓBREGA, M. T.; GASPARETTO, N. V. L.; NAKASHIMA, P. Mapeamento de zonas de riscos à erosão de Cidade Gaúcha - PR. In: I Encontro Geotécnico do Terceiro Planalto Paranaense. 2003, Maringá, Anais... Maringá: UEM, 2003. p. 101-129.

NUNES, J. O. R. Uma contribuição metodológica ao estudo da dinâmica da paisagem aplicada a escolha de áreas para a construção de aterro sanitário em Presidente Prudente SP. 2002. 230 f, Tese (Doutor em Geografia)-Faculdade de Ciências e Tecnologia, Universidade Estadual Paulista, Presidente Prudente, 2002.

PANORAMIO. 2013. Disponível em: <http://www.panoramio.com/photo/93662181\#>. Acesso em 8 de dezembro de 2016. 
PRADO, J. P. B.; NÓBREGA, M. T. Determinação de perdas de solo na bacia hidrográfica do Córrego Ipiranga em Cidade Gaúcha, Estado do Paraná, com aplicação da Equação Universal de Perdas de Solo (EUPS). Acta Scientiarum. Technology, Maringá, v. 27, n. 1, p. 33-42, 2005.

SANTOS, C. Cartografia ambiental e planejamento territorial urbano. Patrimônio: Lazer \& Turismo, v. 6, n. 7, p. 40-74, 2009.

SANTOS, H. G., et al. Carta de Solos do Estado do Paraná. Brasília: EMBRAPA, 2008. Escala 1:250000.

SANTOS, R. F. Planejamento ambiental: teoria e prática. São Paulo: Oficina de textos, 2004. 170 p.

SILVEIRA, H. Modificações antrópicas do solo: influência do uso e manejo e reflexos no meio rural do município de Cidade Gaúcha. 1997. 95 f, Dissertação (Mestrado em Geografia)-Faculdade de Ciências e Tecnologia, Universidade Estadual Paulista, Presidente Prudente, 1997.

SOARES, P. C., et al. Ensaio de caracterização estratigráfica do Cretáceo no estado de São Paulo: Grupo Bauru. Revista Brasileira de Geociências, São Paulo, v. 10, n. 3, p. 177-185, 1980.

THOMAS, D. S. G.; GOUDIE, A. The dictionary of Physical geography. 3th Ed. Pondicherry: Blackwell Publishing, 2000. 626 p. 